(C) Springer Nature Switzerland AG 2019. This is a post-peer-review, pre-copyedit version of a chapter published in the 'Values of the University in a Time of Uncertainty'. The final authenticated version is available online at: https://doi.org/10.1007/978-3-030-15970-2_18

\title{
Chapter 13: Improving well-being in Higher Education: Adopting a compassionate approach
}

\author{
Frances A. Maratos, Paul Gilbert, Theo Gilbert.
}

\begin{abstract}
Chapter Overview
This chapter directs attention to increasing calls to integrate compassion training in curricula throughout the education system. Compassion-based initiatives are now beginning to be utilised within a wide range of organisational, health and educational settings. One reason is that a large body of evidence is now well established - and growing rapidly - that demonstrates focusing on the cultivation of compassion-based motives and affiliative emotions has important effects on mental states and well-being. Indeed, compassion training is now known to have a range of physiological effects and improve both moral and prosocial behaviour and to enhance connections between people that are rescuing, sustaining and rational. In universities and schools, the call for compassion training is set against a growing concern with the consequences of the increasingly self-focused competitive nature of education.
\end{abstract}

While some degrees of competitiveness can be useful, individuals who are overdriven in competitiveness can become narcissistic and callous, while those who feel they are failing can become stressed, self-critical, anxious, depressed and generally mentally unwell (Gilbert P, 2009, 2017a). In Higher Education (HE) it is growing harder and harder to mediate such cultures when neither staff nor students have experience, in their teacher training, nor school backgrounds, of even a basic education in the psychobiological nature of compassion. Key players in government too appear to misunderstand or overlook how such a grounding plays a vital role in combining socio-emotional and subject education. Compassion builds mental and emotional resilience.

In this chapter we review current HE aims and objectives, and the potential psychological impacts that a metric-based educational system can have on both staff and students, including the values it creates. We also outline the importance of having a clear understanding of the nature of compassion as a form of courage and focus, and explore the processes and evidence for a particular form of compassion training - 'compassionate mind training' or 'CMT' - on wellbeing, including in terms of social relating. In addition, we discuss how to implement compassion-based practices in HE, enabling universities to embrace the core values they often advertise, e.g. statements suggesting they champion the health and well-being of their communities, as well as academic performance. In sum, we argue that elements of compassion should underpin the training of lecturers (and teachers), as well as students (and pupils), if UK institutes of learning are to truly embrace the core values they advertise, and promote the health and well-being of their staff and student body. 
(C) Springer Nature Switzerland AG 2019. This is a post-peer-review, pre-copyedit version of a chapter published in the 'Values of the University in a Time of Uncertainty'. The final authenticated version is available online at: https://doi.org/10.1007/978-3-030-15970-2_18

\section{1: Higher Education and the Concept of Compassion}

The landscape of higher education is changing. The shift to funding through student tuition fees combined with the lifting of student quota controls has led to a competitive market, where universities increasingly allocate much larger monetary amounts to capital investment (i.e. marketing and advertising, as well as redesigning buildings/infrastructure etc.) and senior management pay (UCU, 2018). Concurrent with this is the metricisation of higher education, with UK universities competing for top-ranking research status (as measured via the Research Excellence Framework, 2018), top-ranking teaching status (as measured via the Teaching Excellence Framework, 2018), and most recently their ability to demonstrate transfer of knowledge out of academia (in accordance with the yet to be finalised 'Knowledge Exchange Framework', 2018). According to Universities UK (2018), a key idea of this metricisation is to enable a consistent approach to research, teaching and knowledge exchange in higher education across the UK - yet to what detriment?

Potentially, a system of metricisation comes with the de-professionalisation of teaching and research, where innovative pedagogical practices are feared by academics (given the potential for poor student ratings, despite greater learning); and research is increasingly guided by the strategic aims of the specific university and/or academic department rather than the domain of the academic. Bizarrely, however, for staff, this is at odds with a number of UK university aims and objectives (as of June $29^{\text {th }}, 2018$ ), which state they are a place of providing 'innovation' for their students (e.g. University of Huddersfield, Imperial College London, University of Birmingham, University of Bristol, Durham University, etc.) or 'personalised students' learning experiences' (e.g. University of Nottingham, University of Oxford).

For the student, a system of metricisation, potentially leads to the narrow focus of higher education becoming the pursuit of qualifications that leads to graduate employment, as measured by a further metric the 'Destination of Leavers from Higher Education' (2018). Here, transformational values, such as becoming an inspired learner who actively seeks out broadening knowledge, as well as engages in prosocial behaviour for genuine reasons, is often side-lined in order to prioritise 'assessment-focus' and an encompassing CV. This prioritising of private enterprise is very much echoed in a number of UK University mission and/or value statements e.g., as of June $29^{\text {th }}, 2018$, 'to produce graduates distinguished by 
(C) Springer Nature Switzerland AG 2019. This is a post-peer-review, pre-copyedit version of a chapter published in the 'Values of the University in a Time of Uncertainty'. The final authenticated version is available online at: https://doi.org/10.1007/978-3-030-15970-2_18 their intellectual capabilities' (University of Manchester), 'educating our students to become future leaders' (University of Bath), 'to be the best in all we do' (University of Southampton) and the value of 'ambition and drive' (University of Warwick),

Given these conflicting aims and objectives of UK universities for academic staff, and the highly competitive nature of HE to students and staff alike, it is unsurprising that the well-being of University staff and students is a current focus of attention. This includes the formation of the 'Education Support Partnership' in 2015, which claims to be 'the only charity dedicated to improving the health and wellbeing of the entire education workforce' and Universities UK in December 2016, introducing a new programme to address mental health and wellbeing in universities, with major aims including: to: i) 'Set out the case for institutions to see mental health as a strategic priority and to develop a whole-institution framework in support' and ii) 'Establish baseline data on the mental health of our populations and the effectiveness of interventions in place'. [Embolded text, authors own.]

Importantly, one potential type of mental-health initiative/intervention that is not only demonstrating a range of beneficial effects, including the promotion of prosocial behaviour (e.g. Kirby \& Gilbert P, 2017; Ricard, 2015; Singer \& Bolz, 2012), is that based on the ethos of compassion, and in particular compassion-focused therapy (CFT) and compassionate mind training (CMT). CMT is demonstrating increased utility in applied settings including education. For example, based on both CFT and CMT, a pragmatic understanding of the micro skills of compassion - a compassion-focused pedagogy (CfP) - has been developed for HE group and team work. Using extensive ethnographic studies of HE classroom behaviours in various disciplines, these evidence-based micro skills have been studied for their effects on student social and learning experience in group work with comparisons made between intervention and control groups (Gilbert, 2016; Doolan et al, under review). Based on results so far, this kind of CfP is being used and explored further in some universities as a practical approach to students' management of their group work ${ }^{1}$. However, to understand why CFT and CMT initiatives are gaining favour (as well as results) in applied settings, it is necessary to first briefly outline what compassion is, its premises as an intervention and its growing evidence base.

\section{Understanding the nature and functions of compassion}

\footnotetext{
${ }^{1}$ https://www.youtube.com/watch?v=3jFVTCuSCOg
} 
(C) Springer Nature Switzerland AG 2019. This is a post-peer-review, pre-copyedit version of a chapter published in the 'Values of the University in a Time of Uncertainty'. The final authenticated version is available online at: https://doi.org/10.1007/978-3-030-15970-2_18

The evolution of compassion owes its origins to the evolution of caring behaviour between infant and parent (Mayesless 2016). This major shift in reproductive strategies was to have a profound effect on the subsequent evolution of mammalian species, partly because of the social challenges and opportunities that interpersonal closeness created (Gilbert, $\mathrm{P}$ 1989/2016; Mikulincer \& Shaver, 2007). Evolution created physiological systems that enabled parents to be sensitive and responsive to the needs and distress of their infants and for infants to be physiologically organised around inputs from the parent. Over the subsequent 100 million years evolution adapted these physiological mechanisms significantly, such that distress responsiveness and preparedness to help, even by putting oneself at risk, now operates in a range of relationships. For example, all medical and rescue services depend on this fundamental motive. Similarly, while some individuals may go into teaching as a 'job' others choose it as a vocation because they have a genuine interest in helping support the learning of the next generations. Many studies have revealed that the desire to be helpful to others is one of humans' most meaningful goals (Gilbert P, 2009, 2017b; Ricard, 2015).

It is now well recognised that caring behaviour in contrast to competitive behaviour organises a range of physiological systems in very different ways, and supports moral behaviour and well-being in a way that self-focused competitiveness may not (e.g. Weng, Lapate, Stodola, Rogers \& Davidson, 2018; Weng, Fox, Shackman et al., 2013). In addition, being a recipient of caring behaviour has major physiological effects which are quite different from experiencing oneself as a competitor with potentially indifferent or even critical and hostile others (Gilbert, P, 2017ab, 2018). It is additionally now known that early life experiences associated with caring behaviour have a range of impacts including gene expression, immune system functioning, cardiovascular functioning, and maturation of the autonomic nervous system/frontal cortex to name just a few (Cowan, Callaghan, Kan Richardson, 2016). Importantly too, children who grow up in a secure, caring environment in contrast to a neglectful or hostile one, demonstrate quicker learning, and are more flexible, creative and demonstrate greater explorative play (Mikulincer \& Shaver 2016).

\section{Compassion heightens pro-social cognitive competencies}

Compassion is more than caring though, and utilises specific human cognitive competencies. To expand, about 2 million years ago our human ancestors began to evolve very rapidly new types of brain that enabled new types of cognition. This involved self- 
(C) Springer Nature Switzerland AG 2019. This is a post-peer-review, pre-copyedit version of a chapter published in the 'Values of the University in a Time of Uncertainty'. The final authenticated version is available online at: https://doi.org/10.1007/978-3-030-15970-2_18 awareness, abilities to reason and think systematically, abilities to use symbols and language and, critically, the ability to develop knowing intentionality. When these new cognitive competencies are used in the service of caring they are called compassion (Gilbert P, 2017b). So compassion can be defined as a motivation that is focused on the sensitivity to suffering in self and others, with a commitment to try to alleviate and prevent it (Gilbert P \& Choden, 2013; Gilbert P, 2009). With respect to this there are two elements; these are stimulus detection and response proficiency. First is stimulus sensitivity whereby different stimuli activate and orientate attention which, for compassion, is some kind of need or distress. Second is response proficiency. This is the capacity for empathically understanding what would be helpful in that specific context. This definition clearly highlights that compassion is more than just intentionality. To illustrate, seeing somebody fall into a river and, consequently, jumping in to save them may be a compassionate intention but it will be ineffective, and potentially even problematic, if one cannot swim. In this case, one lacks the wisdom of knowing how to behave or act appropriately. This is where compassion training underpins effective and helpful behaviours, as well as social relating, by enabling individuals the skills to develop compassion for themselves, as well as compassion for others, and being open to compassion from others.

Compassion training focuses on how to orientate to need and/or distress in both the self and others, and how to work out appropriate empathic responses. Individualistically competitive environments, however, tend to do the opposite and close down interest in the needs and distress of others in favour of self-focused achievement and concern with selfpresentation and positive social comparison. For example, Crocker and Canevello (2008, 2012) asked University students to rate the degree programme they were taking, in terms of "compassionate" goals such as wanting to be helpful to people and being sensitive to their needs in contrast to "self-image" motives and goals, such as wanting others to see that you are right and avoid showing mistakes. Results revealed that these two motivations were related to quite different potentials for social and mental health outcomes. Compassionate goals were linked to feeling connected, to lower levels of conflict, and better mental health. Conversely, self-image goals were negatively related to these outcomes. Indeed, the more self-focused, competitive and shame-focused individuals are, the more prone to depression they may be (Crocker, Canevello, Breines, \& Flynn, 2010).

There are a number of slightly different approaches to compassion training all of which have some evidence to support them (Kirby, 2017; Kirby \& Gilbert P, 2017; Seppälä, Simon- 
(C) Springer Nature Switzerland AG 2019. This is a post-peer-review, pre-copyedit version of a chapter published in the 'Values of the University in a Time of Uncertainty'. The final authenticated version is available online at: https://doi.org/10.1007/978-3-030-15970-2_18 Thomas, Brown, Worline, Cameron \& Doty, 2017). One is called compassionate mind training (CMT), which forms part of compassion focused therapy (CFT) developed for individuals who have high levels of self-criticism and shame and/or are vulnerable to depression and anxiety (Gilbert P, 2009, 2010). However, whereas CFT involves developing a therapeutic relationship and detailed formulation of a particular problem, then tailoring interventions for the specific individual, CMT is a set of practices and psychoeducation that are designed to cultivate both physiological and psychological processes that are conducive to well-being, creativity, moral and prosocial behaviour, and can be utilised outside of a therapeutic setting as well as in larger group settings including in schools, colleges and universities and for staff as well as students (Gilbert, 2009; Gilbert T, 2016; Maratos et al., under review).

CMT is an integrative and multidimensional approach to compassionate mind training that includes: emotion and body awareness, breathing and voice tone practices to stimulate affiliative physiology (Arch et al., 2014; Chang, Liu \& Shen, 2013; Maratos \& Sheffield, in preparation), a range of attentional, imagery and behavioural practices to promote compassion (Duarte, McEwan, Barnes, Gilbert \& Maratos, 2015; Rockliff et al., 2008) as well as education as to the nature of 'being human' drawn from research science (e.g. neuroscience, evolutionary psychology, social psychology, developmental psychology etc., see Gilbert P, 2014; Richardson, McEwan, Sheffield \& Maratos, 2016) .

Additionally, and also of key importance, CMT focuses on three orientations of compassion. Firstly, there is the compassion we can feel for others and how we seek to reach out to others; and there is now increasing evidence that practising being helpful to others has major impacts on our physiological systems that are conducive to well-being and brain changes (Weng et al., 2018). Second is being open and receptive to compassion from others including experiencing joyful (not obligatory) gratitude (Wood, Froh \& Geraghty, 2010). Here again this is linked to a large literature on the value of feeling supported and cared for in one's personal environment (Wang, Cai, Qian, \& Peng, 2014). Third is our ability to be selfcompassionate rather than harshly self-critical. It is known, for example, that it is not so much the content of criticism but the emotional tone of criticism that is harmful (Gilbert, P, 2010). Adding to this, it is when criticism becomes hostile or contemptuous that depression is more likely. Hence compassionate mind training teaches individuals to be sensitive to the emotional tone of their own thinking and try to generate a friendly rather than hostile tone (ibid). 
(C) Springer Nature Switzerland AG 2019. This is a post-peer-review, pre-copyedit version of a chapter published in the 'Values of the University in a Time of Uncertainty'. The final authenticated version is available online at: https://doi.org/10.1007/978-3-030-15970-2_18

There is now evidence that even a very short-term ( 2 week) intervention based on this style of training has a range of beneficial effects including decreased reports of stress, increased reports of compassion (to the self and others) and improved heart rate variability; the latter being an indicator of increased physiological well-being (Matos, Duarte, Duarte, Gilbert P \& Pinto-Gouveia, 2017; Matos, Duarte, Duarte, Pinto-Gouveia, Petrocchi, Basran, \& Gilbert P, 2017; see also Kirby, Tellegen, \& Steindl, 2017). If the aim of education is to create a secure, safe and encouraging base for learning that promotes not only critical thinking, but also moral and ethical awareness, then addressing the dynamics of how to create a conducive environment for this is key. This is especially important given the changing nature of educational environments, particularly the move towards an overly self-focused 7competitive and threat-based educational system in the UK over recent decades that was noted above. Indeed, many of the increases in poor mental health and suicide in student populations appear to be linked to fears of failing in this intense competitive environment (see, for example, Hjeltnes, Binder, Moltu \& Dundas, 2015).

We consider the adverse effects of these educational environments in a little more detail, in section 13.2. Then in section 13.3 we detail how CMT has recently been shown to be effective in school settings and in section 13.4 how compassion-focused pedagogy (CfP) is being created in the modern context of Higher education ${ }^{2}$.

\section{2: The Need for Compassion Based Initiatives in Educational Settings}

In the context of HE, the Times Higher Education (July, 2018) reports Professor Gail Kinman's recent finding that over half of a sample of 6,539 university teaching staff had experienced levels of mental health-damaging stress. (Only staff in the prison sector, she points out, experience more.) Untenable workloads, including being required to mark 418 scripts in 20 days for example - pushed a UK university's father of three, Dr Malcolm Anderson, to commit suicide in February (Grove, 2018). Only months later, in June the UK's Universities Minister delivered a speech to the country's Higher Education Policy Institute on the need for some HEI's to work harder on "Delivering Value for Money" - with none of the above reality factored in (Gyimah, 2018). Schools, colleges and universities are championed as learning environments that facilitate creating a safe and secure base for teaching and

\footnotetext{
${ }^{2}$ In this paper the taught and assessed use of the micro skills of compassion for use in group work, are only one example of a burgeoning development of empirically driven, CMT-based, compassion-focussed pedagogy that is being developed in some universities.
} 
(C) Springer Nature Switzerland AG 2019. This is a post-peer-review, pre-copyedit version of a chapter published in the 'Values of the University in a Time of Uncertainty'. The final authenticated version is available online at: https://doi.org/10.1007/978-3-030-15970-2_18 learning, cultivate critical reasoning, and promote prosocial behaviour/moral awareness as part of the educational experience. But this is too often not the case for either staff or students.

Indeed, the individualistically competitive nature of the working and learning environment, and its impact on student, as well as staff, mental health is increasingly evident in universities. Levels of clinical anxiety and depression amongst students globally continue to rise (Hamilton and Schweitzer, 2000; Mitsui et al. 2013). The HE sector in England and Wales is no exception (You.Gov, 2017), and increasing numbers of student suicides are reported by the Office of National Statistics (2017). In the first months of 2018, for example, the UK media's coverage of seven student suicides in a single UK university in just eighteen months galvanised public protest at the neoliberal model of a marketised, business-minded, profit-focussed HE sector, when HE's original fundamental purpose is to serve the public good. The Vice-Chancellor of the above university has pointed out quite rightly, that these human disasters are a feature of the HE sector as a whole. There are around 130 universities in the UK. It is argued, mostly by a currently right-wing government, that a business model for HE is perfectly acceptable. This is irrational. Governments in most countries would be constrained by law to close down any business whose service product was so frequently associated with customer deaths.

Mirroring HE, there is also growing evidence that primary and secondary schools are becoming increasingly stressful environments for both teachers and pupils. In primary education (7-11 years), rates of anxiety and panic attacks are on the rise, with an increase of $78 \%$ over the past two years (The Key, 2017). Adolescent mental health issues, including teenage suicide, are also on the rise. Here, Rodway et al. (2016) indicate antecedents include exam pressures in $27 \%$, and bullying in $22 \%$, of cases. More general reports reveal an increase in fear of academic failure (76\%) and depression (55\%), among these young populations (Mental Health Foundation, 2016), as well as a significant impact on pupils' capacity for learning.

In respect to teacher health, a recent UK government report states that $30 \%$ of teachers left the profession within the first five years for reasons of excessive workload and bureaucracy (Carmichael, 2017). Consistent with this, the Educational Support Partnership (2017) survey of over 1,250 education professionals revealed that three quarters $(75 \%)$ report experiencing physical and mental health issues in the last two years because of stress and their poor work-life balance. According to NASWUT (2016), 77\% of teachers further feel 
(C) Springer Nature Switzerland AG 2019. This is a post-peer-review, pre-copyedit version of a chapter published in the 'Values of the University in a Time of Uncertainty'. The final authenticated version is available online at: https://doi.org/10.1007/978-3-030-15970-2_18 that there is a widespread behaviour problem in schools, with over half $(51 \%)$ suggesting they are not given appropriate training, information or advice to help them deal with difficult pupil behaviour. Whilst the government has now started to make moves to address such issues (e.g. 200K for mental-health first-aiders, Bloom, 2017), teacher and pupil stress, combined with problematic pupil behaviour, are now endemic within the UK.

Perhaps unsurprisingly, competitive pressures have been highlighted as a major source for such pupil and staff difficulties in schools. Not dissimilar from the metricisation of HE, the introduction of open performance school league tables in the UK leads to prioritisation of student academic achievement above all else, for senior leaders, teachers and parents alike (see for example: https://www.gov.uk/school-performance-tables). However, there is mounting evidence that classrooms fostering social comparison and competitive self-interest, in contrast to cooperative and mutually supportive learning, are associated with increased occurrences of bullying (Di Stasio, Savage, \& Burgos, 2016). Additional consequences of this 'academic results' focus include increasing self-focused competitive stress, fear of failure, shame and exclusion; all of which can undermine mental well-being and performance (Crocker, Canevello, Breines, \& Flynn, 2010; Irons, \& Gilbert P, 2005).

\subsection{The Implementation of Compassion Based Initiatives in Primary and Secondary Educational Settings}

Recognising the growing problems of competitive stress in schools, a growing number of well-being initiatives are beginning to primarily address well-being, transformative values and/or compassion ${ }^{3}$. More widely, Thich, Nhat, Hanh \& Weare, (2017) provide educative and informative materials directed towards teachers (of all levels) to improve both their own and their pupils' well-being (see also Al-Ghabban, 2018; Coles 2015; Lavelle, Flook, \& Ghahremani 2017). Considering CMT specifically, Welford and Langmead (2015) have developed 'Care to Achieve', a compassion based initiative which integrates core CMT tenets within a school-based setting. Results demonstrate that Care to Achieve has led to: an increase in staff well-being (via self-report and a decrease in sickness); an increase in parental engagement (measured by increased parental attendance in school for a range of activities); and a decrease in low level disruptive behaviour and fixed-term exclusions.

\footnotetext{
3 e.g. 'The big picture' (Educational Endowment Foundation, https://educationendowmentfoundation.org.uk/school-themes); the Child Outcomes Research Consortium (https://www.corc.uk.net/) and the Mindfulness in Schools Project, University of Southampton (https://mindfulnessinschools.org/research/).
} 
(C) Springer Nature Switzerland AG 2019. This is a post-peer-review, pre-copyedit version of a chapter published in the 'Values of the University in a Time of Uncertainty'. The final authenticated version is available online at: https://doi.org/10.1007/978-3-030-15970-2_18 Welford and Langmead (2015) acknowledge that the uptake of the approach, disseminated by word of mouth, highlights the potential credibility and attractiveness of compassion based initiatives in the UK. However, as declared by the authors themselves, there remains a need for further rigorous scientific evaluation of such approaches.

Taking this forward, Maratos et al. (under review) have designed, progressed and scientifically evaluated a 6 module compassionate mind training initiative with the entire staffing population $(n=78)$ of a UK secondary school. Based upon the three core principles of CFT, this initial 'action research' included a blend of psychoeducation, imagery practices and group or dyadic based exercises. Whilst primarily a proof of concept study to investigate the feasibility and efficacy of CMT in UK school settings, the initiative was comprehensively evaluated using a mixed methods approach - with several positive results. For example, the CMT curriculum was well-received by staff, with the majority (over $90 \%$ ) reporting that they would recommend the training to others. In terms of actual impact effectiveness, quantitative data revealed that those who practiced the CMT exercises demonstrated significant increases in self-compassion and significant decreases in self-criticism. Adding to this, qualitative exploration of the initiative revealed that staff were satisfied with the CMT activities, with a major theme emerging, i.e. 'The potentials of using CMT to deal with emotional difficulties'.

To sum, introducing secondary school teachers and staff to compassionate mind training (that has different elements of recognising emotions, mindfulness and developing compassion motivation for dealing with stress), proved very successful on a number of grounds. Thus, in evaluating this proof of concept research, Maratos et al., (under review) argue that compassionate mind training holds much promise as a way of helping school staff (and especially teachers) counteract the current competitive nature of education, and learn ways to counteract stress; especially that associated with self-criticism and anger rumination that contributes to burnout. However, what is now needed is a curricula suitable for mass rollout both nationally and internationally, as well as pupil-friendly versions of the initiative, and, importantly, a curricula that is designed specifically for the challenges of students and staff within the HE sector. The need for such a bespoke HE curricula and steps being made towards this (e.g. the micro skills of compassion), are outlined below.

Pg. 9-10)

\section{4: Promoting and Assessing Compassion in Higher Education}


(C) Springer Nature Switzerland AG 2019. This is a post-peer-review, pre-copyedit version of a chapter published in the 'Values of the University in a Time of Uncertainty'. The final authenticated version is available online at: https://doi.org/10.1007/978-3-030-15970-2_18

In addition to the adverse effects of education as a competitive process outlined above, a key contributor to the fatal distress amongst some HE students today is thought to be their low levels of social integration on campus, especially for black, ethnic minority and international (BME) students [UK National Union of Students (NUS), 2010].

It is in the class room, the NUS has concluded from its watershed study (2010), that FE and HE must work harder "to promote social cohesion and better integrate their student bodies" (p61). In particular, it looks to FE and HE to recognise that "social inclusion" and "social cohesion" (p61) "could be achieved by increasing discussion and interactive work within the classroom" (p61).

Academic staff and student led initiatives, increasingly in partnership, are trying to address this in many universities and Advance HE in the UK is encouraging co-operation and connection across UK universities in this regard. There are now a range of such partnerships that are focussing efforts on ungluing HE from its over reliance on 'the traditional lecture' and in particular, on the ubiquitous traditional written essay as a means of assessment. Both are too often linked to an inward-facing (Anglo/ethno-centric) curriculum that requires students to read texts that are predominantly written by white men. Lectures are derived from medieval times when a precious single text, possibly hand written, was the responsibility of the male university educator (or monk) to read aloud to male listening students. and students listened. This kind of approach and the kinds of material it often relies on hardly facilitates the ideation of multiple, alternative, innovative perspectives in student minds' (cf. University straplines) when they are thinking about the target subject. Thus, is it not only for the reasons pointed out above by the NUS that a growing number of university staff are trying to diversify their teaching and assessment practice to include team based learning and group work. It is academically appropriate for our times too and in shift-changing disciplines often a prerequisite of the regulatory body (e.g. for accreditation of Psychology degrees in the UK, the BPS specify 'The curriculum requirements ... outline the need for practical work to cover a wide variety of methodologies ... Students should ...engage in practical work. Accredited programmes will be expected to demonstrate the ways in which they accommodate these expectations'(BPS, 2016, p21)).

A delay to progress here, however, is that when (homogenous or diverse) students are required to work together, they have seldom been taught how to do this in ways that - at least where the science of compassion is concerned - are based on an empirical, up to date evidence base. Thus, while guidance may be given to students on referencing, citing and so 
(C) Springer Nature Switzerland AG 2019. This is a post-peer-review, pre-copyedit version of a chapter published in the 'Values of the University in a Time of Uncertainty'. The final authenticated version is available online at: https://doi.org/10.1007/978-3-030-15970-2_18 on, there is no basic training or help with the cognitively demanding processes of group work management. This means that in terms of the universal psychosocial processes that can be experienced by individuals in a team, students are unsure about how to cope with the quiet member in the group who says (or contributes) little or nothing to group discussions, or the person who dominates (or monopolises) team discussions because of over enthusiasm, or anxiety (Yalom, 1985), or individualistic competitiveness and private enterprise (Chickering, 2010); or all of these. These are the very factors that come up again and again in student reports of what has undermined their group's social cohesion and hobbled its academic performance (Gilbert T et al, 2018)

Businesses are urging universities to address this. The Hay Group (2015) report that in their study of business needs they found that: "93\% of businesses believe strong people skills deliver commercial impact [whereas] 51\% of graduates believe people skills get in the way of getting the job done”. In similar research, the British Chamber of Commerce (2014) reported: "Over half (57\%) said that young people are lacking basic 'soft'skills, such as communication and team working, to succeed in the working world.". Yet Google, which has recently spent US\$5M on a study to identify the key defining feature of its highest performing teams (from a sample of 180 teams) found that the key, defining, shared feature was not ambition, a leader, a mix of skills or personalities, experience or qualifications. It was kindness (Duhigg, 2016) and this is what appeared to raise the teams' collective intelligence. The company is joined by IBM, PcW and many other companies investing in ways to accelerate the nurturing of effective in-house team dynamics that attend to safeness in psychosocial processes (The Times Top 100 Graduate Employers.com). This trend is vital for 'business-facing' HE to pay attention to in relation to the rising levels of its key customers' distress and suicides once they try the HE business product. It is also vital to address if universities wish to pay proper attention to ensuring their graduates progress onto graduate positions (i.e. their DELHI statistics).

How is HE therefore, to catch up with businesses, with current research on compassion as a matter of intellectual honesty, and above all, how is it to catch up with its duty to its key customers: students? Its failures in all three areas is becoming increasingly transparent and public.

We argue here, that a vital component of the solution is that the science of compassion - being built now through the work of multiple disciplines - is a force to be reckoned with by HE on the institution's own terms, namely its pre-occupation with the 
(C) Springer Nature Switzerland AG 2019. This is a post-peer-review, pre-copyedit version of a chapter published in the 'Values of the University in a Time of Uncertainty'. The final authenticated version is available online at: https://doi.org/10.1007/978-3-030-15970-2_18 measurement of student academic success. Indeed, it is becoming evident that there is a correlation between compassion on the HE curricula and statistically identified enhancements to academic performance, compared with control groups (Gilbert, T, 2016; Doolan et al, under review). Training of staff and students requires explanation and a little classroom practice - while on subject task - of the simple, observable 'micro skills of compassion' for group/team work. Where HE practitioners develop this kind of compassionate practice amongst their students as part of the in-class teaching and learning experience, increases are observed with respect to student engagement with each other, the subject area and their academic performances, as compared to controls (Gilbert, T. 2016; Gilbert, T., 2017; Doolan et al, under review). It is on these terms that we can discuss how the training of students in the micro skills of compassion in their dealings with each other, regardless of level or subject, can be embedded into the curriculum and made credit bearing towards attainment of the modern university degree.

The University of Hertfordshire (UH) brands itself as 'An international businessfacing university' ( $1^{\text {st }}$ August, 2018) It is committed to working with local and other businesses in areas such as Knowledge Exchange, Research Partnerships with business, and has a strong emphasis on the development of graduate skills around employability. Its business school is the largest in the south east of England. The micro skills of compassion in group work - what they look like in action and their theoretical basis for use in group discussion work - has been researched and trialled in this school (as well as other schools in the university ${ }^{4}$ ). On some modules, students are supported by academic staff in their use of the easily taught micro skills of compassion during task-focussed, timed, face-to-face discussions in seminars and/or tutorials. Then, in final, end of module, filmed small group discussions, students are tutor-assessed individually for: research skills, critical/analytical thinking and, importantly, the use of the micro skills of compassion that they have been taught, and have practiced using in seminars and tutorials throughout the model (See Fig. 1 for assessment criteria for the micro skills of compassion). The use of these micro skills of compassion - including standing down monopolisers when necessary (not silencing them) and drawing in quieter members of the group - are credit bearing towards these students' degrees. With minor adaptions to assessment practice, this is the case on some degree programmes, post and under graduate, in the Schools (departments) of the Humanities,

\footnotetext{
${ }^{4}$ Additionally, a further pilot is underway with students in the Life Sciences (i.e. Psychology) department of the University of Derby.
} 
(C) Springer Nature Switzerland AG 2019. This is a post-peer-review, pre-copyedit version of a chapter published in the 'Values of the University in a Time of Uncertainty'. The final authenticated version is available online at: https://doi.org/10.1007/978-3-030-15970-2_18 Computer Science and Business at the University of Hertfordshire where the research around this CfP has been developed. Staff from, currently, 36 other universities (UK, Canada, USA and Europe) are also now networked and engaging with this form of CfP.

To expand, the Compassionate Mind Foundation's model of compassion, as well as some of its core principles of CMT, have been combined with findings of research into the ethnography of university class room behaviours, with and (for control purposes) - without staff and student exposure to that model. This research included close attention to, and recording of, the often non-verbal, but nevertheless observable details of enactments of compassionate (or non-compassionate) behaviours of students for themselves and others in discussion group work. Here, certain compassionate actions were found again and again to intensify the group's focus on group social cohesion and criticality on task; in other words, inclusivity and intellectual risk taking. The micro skills that facilitated this in student groups in class, including amongst relative strangers, were introduced in the first hour of the module, and thereafter embedded into routine class room discussion practice by staff and students. Thinking then of the HE focus on metricisation, a statistical analysis was made on a module of ethnically diverse business students ( $n=38)$ to identify evidence of: i) negative, positive or no impact of the teaching; and ii) assessing of compassion (as above), on individual student academic performance - specifically in relation to critical thinking. In the essay assignment on the module, critical thinking percentage marks for each individual student clearly mirrored the UK HE sector's overall 14-15\% achievement attainment gap between BME students (and also international students) and local white students. Yet for critical thinking in the context of compassion, as was possible in the discussion groups, no statistical evidence could be found of an attainment gap between white and BME students when all the essays and all the presentations were double marked by two senior business lecturers (Gilbert, 2016). A similar study undertaken amongst $(\mathrm{n}=220)$ computer science undergraduate students, compared to a control has had similar results (Doolan et al, under review).

Thus this research, taken in the context of that evidenced throughout the education sector to date, demonstrates that developing most staff and students in their expert and astute use of the micro skills of compassion in group work, is not only a fast and easy endeavour, but a grounds to improve social-relating (an important transformative skill recognised in real-world settings). One further reason for this is the close-to-the surface appetite in students and staff to stand down from the relentless HE promotion of what Chickering (2010) describes as competitive individualism and private enterprise and promote learning instead. Here is the 
(C) Springer Nature Switzerland AG 2019. This is a post-peer-review, pre-copyedit version of a chapter published in the 'Values of the University in a Time of Uncertainty'. The final authenticated version is available online at: https://doi.org/10.1007/978-3-030-15970-2_18 evidence based, theoretically underpinned component of compassion that can be added to assessment of many types of face to face, interactional group work.

\author{
$* * *$ Figure 1 about here***
}

\title{
13.4 Summary
}

To conclude, much research demonstrates that the cultivation of a compassion-based ethos, and associated practices, has important effects on mental states and well-being. Specifically, the positive effects of compassionate mind training are not only demonstrated in therapeutic based settings, but across both public and private sector settings, with recent compelling evidence emerging of its utility in school-based settings. Added to this, Gilbert, T (2016); Gilbert, (2018); Doolan et al, under review) have revealed evidence of its many benefits in higher education, with the use of the micro skills of compassion in group work. This simple CMT based intervention has been found in studies so far (ibid) to equip and motivate students to seek out ways to enhance each other's social and learning experiences in task focussed groups to degrees they would not normally have been inclined to attempt. The impacts on academic achievement are now coming to light through quantitative data (ibid). Here, there is an alignment with the aims of universities that are striving to ensure students are fit for graduate employment, as well as able to cope with championing HE's remit to serve the public good through enhanced pro-social thinking processes in groups and communities. Schools and universities alike are more likely to meet their own stated aims if they attend with absolute attention to catching up with a now formidable body of evidence of the role of compassion in education. If this is done then their current aims (and values) may evolve too. This is why we resolutely argue for embedding compassion into school and HE environments. If UK institutes of learning truly embrace the core values they advertise, they will attend to the science of compassion to nurture and protect the health and well-being and thus irreplaceable talents - of their staff and student bodies. 
(C) Springer Nature Switzerland AG 2019. This is a post-peer-review, pre-copyedit version of a chapter published in the 'Values of the University in a Time of Uncertainty'. The final authenticated version is available online at: https://doi.org/10.1007/978-3-030-15970-2_18

\section{References}

Al-Ghabban, A. (2018). A compassion framework: the role of compassion in schools in promoting well-being and supporting the social and emotional development of children and young people. Pastoral Care in Education, 1-13.

Arch, J. J., Brown, K. W., Dean, D. J., Landy, L. N., Brown, K. D., \& Laudenslager, M. L. (2014). Self-compassion training modulates alpha-amylase, heart rate variability, and subjective responses to social evaluative threat in women. Psychoneuroendocrinology, 42, 49-58.

Bloom (2017) Government puts 200k behind plan for mental health first-aiders in every secondary. Retrieved from: https://www.tes.com/news/government-puts-ps200kbehind-plan-mental-health-first-aiders-every-secondary

British Chamber of Commerce, The. Young people need more support to make transition from education to work. Retrieved from: http://www.britishchambers.org.uk/pressoffice/press-releases/young-people-need-more-support-to-make-transition-from-education-towork,-says-bcc.html

Carmichael (2017) Recruitment and retention of teachers. Retrieved from: https://publications.parliament.uk/pa/cm201617/cmselect/cmeduc/199/199.pdf

Chang, Q., Liu, R., \& Shen, Z. (2013). Effects of slow breathing rate on blood pressure and heart rate variabilities. International journal of cardiology, 169(1), e6-e8.

Chickering, A. W. (2010). A retrospect on higher education's commitment to moral and civic education. Journal of College and Character, 11(3), 1-6.

Coles, M.I (2015) Towards the Compassionate School. From Golden Rule to Golden Thread. London: Institute of Education press.

Cowan, C. S. M., Callaghan, B. L., Kan, J. M., \& Richardson, R. (2016). The lasting impact of early-life adversity on individuals and their descendants: potential mechanisms and hope for intervention. Genes, Brain and Behavior, 15(1), 155-168. 
(C) Springer Nature Switzerland AG 2019. This is a post-peer-review, pre-copyedit version of a chapter published in the 'Values of the University in a Time of Uncertainty'. The final authenticated version is available online at: https://doi.org/10.1007/978-3-030-15970-2_18

Crocker, J. \& Canevello, A. (2008). Creating and undermining social support in communal relationships: The role of compassionate and self-image goals. Journal of Personality and Social Psychology, 95, 555-575.

Crocker, J., \& Canevello, A. (2012). Consequences of self-image and compassionate goals. In P. G. Devine, and A. Plant (Eds.), Advances in experimental social psychology (pp. 229-277). New York: Elsevier.

Crocker, J., Canevello, A., Breines, J.G., \& Flynn, H. (2010). Interpersonal goals and change in anxiety and dysphoria in first-semester college students. Journal of Personality and Social Psychology, 98, 1009-1024.

Destination of Higher Leavers (2018). Experts in UK higher education data and analysis, and the designated data body for England. Retrieved from: https://www.hesa.ac.uk/

Di Stasio, M. R., Savage, R., \& Burgos, G. (2016). Social comparison, competition and teacher-student relationships in junior high school classrooms predicts bullying and victimization. Journal of adolescence, 53, 207-216.

Doolan, M., Gilbert, T., Beka, s., Spencer, N., Crotta, M \& Davari, S. (Under review) Compassion on university degree programmes at a UK University: The neuroscience of effective Group work. Special Issue: Neuroscience of Learning and Development:

Implications for the Design and Evaluation of Student Learning and Development. Journal of Research in Innovative Teaching and Learning ISSN: 2397-7604 Emerald Publishing

Duarte, J., McEwan, K., Barnes, C., Gilbert, P., \& Maratos, F. A. (2015). Do therapeutic imagery practices affect physiological and emotional indicators of threat in high self-critics?. Psychology and Psychotherapy: Theory, Research and Practice, 88(3), 270-284.

Duhigg, C. (2016). What Google learned from its quest to build the perfect team. The New York Times Magazine. Retrieved from: http://www.nytimes.com/2016/02/28/magazine/what-google- learned-from-its-quest-tobuild-the-perfect-team

Education Support Survey (2017). 2017 Health Survey. Retrieved from: https://www.educationsupportpartnership.org.uk/resources/research-reports/2017-healthsurvey

Gilbert, P. (1989/2016). Human Nature and Suffering. London: Routledge

Gilbert, P. (2009). Introducing compassion-focused therapy. Advances in psychiatric treatment, 15(3), 199-208. 
(C) Springer Nature Switzerland AG 2019. This is a post-peer-review, pre-copyedit version of a chapter published in the 'Values of the University in a Time of Uncertainty'. The final authenticated version is available online at: https://doi.org/10.1007/978-3-030-15970-2_18 Gilbert, P. (2010). Compassion focused therapy: The CBT distinctive features series. London: Routledge.

Gilbert, P. (2014). The origins and nature of compassion focused therapy. British Journal of Clinical Psychology, 53(1), 6-41.

Gilbert, P. (2017a). Compassion: Concepts, Research and Applications. London: Routledge.

Gilbert, P. (2017b). Compassion as a social mentality: An evolutionary approach. In: P. Gilbert (ed). Compassion: Concepts, Research and Applications. (p. 31-68). London: Routledge

Gilbert. P. (2018). Living Like Crazy. York: Annwyn House.

Gilbert, T. (2018). Compassion-in-HE. Available at: https://compassioninhe.wordpress.com/, University of Hertfordshire

Gilbert, P \& Choden (2013). Mindful Compassion. Using the power of Mindfulness and Compassion to Transform our Lives. Little: Brown Book Group.

Gilbert, T. (2017) When looking is allowed: What compassionate group work looks like in a UK university. In P. Gibbs (Ed.) The Pedagogy of Compassion at the Heart of Higher Education. Springer: London. Chapter 13, pp 189-202.

Gilbert, T. (2016) Assess compassion in Higher Education? Why and how would we do that? LINK, 2(1). Available at:

www.herts.ac.uk/link/volume-2,-issue-1/assess-compassion-in-higher-education-how-andwhy-would-we-do-that/

Grove, J (2018). Half of UK academics 'suffer stress-linked mental health problems': Scholars at greater risk of stress-related illness than police, medics and local authority staff, research suggests. Times Higher Education Retrieved from: https://www.timeshighereducation.com/news/half-uk-academics-suffer-stress-linked-mentalhealth-problems

Gyimah, S. (2018) Delivering value for money in the age of the student. Speech: The Universities Minister calls for a better deal for students at the HEPI annual conference. Retrieved from: https:/www.gov.uk/government/speeches/delivering-value-for-money-inthe-age-of-the-student. 
(C) Springer Nature Switzerland AG 2019. This is a post-peer-review, pre-copyedit version of a chapter published in the 'Values of the University in a Time of Uncertainty'. The final authenticated version is available online at: https://doi.org/10.1007/978-3-030-15970-2_18

Hamilton, T.K. \& Schweitzer, R.D. 2000, "The cost of being perfect: perfectionism and suicide ideation in university students", Australian and New Zealand Journal of Psychiatry, vol. 34, no. 5, pp. 829-835.

Hjeltnes, A., Binder, P. E., Moltu, C., \& Dundas, I. (2015). Facing the fear of failure: An explorative qualitative study of client experiences in a mindfulness-based stress reduction program for university students with academic evaluation anxiety. International journal of qualitative studies on health and well-being, 10(1), 27990.

Irons, C \& Gilbert, P. (2005). Evolved mechanisms in adolescent anxiety and depression. The role of attachment and social rank systems. Journal of Adolescents, 28, 325341.

Kirby, J. N. (2017). Compassion interventions: the programmes, the evidence, and implications for research and practice. Psychology and Psychotherapy: Theory, Research and Practice, 90(3), 432-455.

Kirby, J., \& Gilbert, P. (2017). The emergence of the compassion focused therapies. Compassion: concepts, research and applications. London: Routledge, 258-85.

Kirby, J.N., Tellegen, C.L., \& Steindl, S. (2017). A systematic review and metaanalysis of compassion-based interventions: Current state of knowledge and future directions. Behavior Therapy. http://dx.doi.org/10.1016/j.beth.2017.06.003

Knowledge Exchange Framework (2018). Retrieved from www.hefce.ac.uk.

Lavelle, B.D., Flook, L., \& GhahremaniIn, D.G (2017). A call for compassion and care in education : toward a more comprehensive prosocial framework for the field Seppälä, E.M., Simon-Thomas, E., Brown, S.L., Worline, M.C., Cameron, L \& Doty, J. R. (Eds). The Oxford Handbook of Compassion Science. (p.475-483). New York: Oxford University Press.

Maratos, F.A., Montague, J. Aziz, H., Welford, M., Gilbert, P., Wood, W., Barnes, C. $\&$ Sheffield, D. (submitted). Compassion in the classroom: Evaluation of a compassionate mind training intervention with school staff to improve well-being

Maratos, F.A. \& Sheffield, D. (in preparation) Brief compassion focused imagery dampens anticipation of and physiological response to pain.

Matos, M., Duarte, J., Duarte, C., Gilbert, P., \& Pinto-Gouveia, J. (2017). How One Experiences and Embodies Compassionate Mind Training Influences Its Effectiveness. Mindfulness, 1-12.

Matos, M., Duarte, C., Duarte, J., Pinto-Gouveia, J., Petrocchi, N., Basran, J., \& Gilbert, P. (2017). Psychological and physiological pffects of Compassionate Mind Training: 
(C) Springer Nature Switzerland AG 2019. This is a post-peer-review, pre-copyedit version of a chapter published in the 'Values of the University in a Time of Uncertainty'. The final authenticated version is available online at: https://doi.org/10.1007/978-3-030-15970-2_18 A Pilot Randomised Controlled Study. Mindfulness, 8(6), 1699-1712.

Mayseless, O. (2016). The Caring Motivation: An Integrated Theory: Oxford, Oxford University Press

Mikulincer, M., \& Shaver, P. R. (2016). Attachment in adulthood: Structure, dynamics, and change (2nd ed.). New York: Guilford Press.

Mental Health (2016) Fundamental Factos about Mental Health 2016. Retrieved from: https://www.mentalhealth.org.uk/sites/default/files/fundamental-facts-about-mental-health2016.pdf

Mitsui, N., Asakura, S., Inoue, T., Shimizu, Y., Fujii, Y., Kako, Y., Tenaka, T, Obe, K. T. Inoue, Kusumi, I. (2013). Temperament and character profiles of Japanese university student suicide completers. Comprehensive Psychiatry, 54(5), 556-561.

doi:10.1016/j.comppsych.2012.11.002

National Union of Students (2010) Race for Equality. Retrieved from: https://www.nus.org.uk/en/news/race-for-equality/

Office of National Statistics (GB) (2017) Student suicides in those aged 18 and above, by sex and usual place of residence, deaths registered in England and Wales between 2001 and 2015. Retrieved from:

https://www.ons.gov.uk/peoplepopulationandcommunity/birthsdeathsandmarriages/deaths/ad hocs/005991studentsuicidesinthoseaged18yearsandabovebysexandusualplaceofresidenceindic atordeathsregisteredinenglandandwalesbetween2001 and2015

Research Excellence Framework 2021 (2018). Retrieved from http://www.ref.ac.uk/

Ricard, M (2015) Altruism. The Power of Compassion to Change Itself and the World. London Atlantic Books

Richardson, M., McEwan, K., Maratos, F., \& Sheffield, D. (2016). Joy and calm: how an evolutionary functional model of affect regulation informs positive emotions in nature. Evolutionary Psychological Science, 2(4), 308-320.

Rockliff, H., Gilbert, P., McEwan, K., Lightman, S., \& Glover, D. (2008). A pilot exploration of heart rate variability and salivary cortisol responses to compassion-focused imagery. Journal of Clinical Neuropsychiatry, 5(3), 132-139.

Rodway, C., Tham, S. G., Ibrahim, S., Turnbull, P., Windfuhr, K., Shaw, J., \& Appleby, L. (2016). Suicide in children and young people in England: a consecutive case series. The Lancet Psychiatry, 3(8), 751-759. 
(C) Springer Nature Switzerland AG 2019. This is a post-peer-review, pre-copyedit version of a chapter published in the 'Values of the University in a Time of Uncertainty'. The final authenticated version is available online at: https://doi.org/10.1007/978-3-030-15970-2_18

Singer, T. \& Bolz, M. (2012) Compassion: Bridging Practice and Science. Retrieved from: http://www.compassion-training.org/?lang=en\&page=about

Seppälä, E.M., Simon-Thomas, E., Brown, S.L., Worline, M.C., Cameron, L \& Doty, J. R. (Eds). The Oxford Handbook of Compassion Science. New York: Oxford University Press

Teaching Excellence Framework (2018). Retrieved from www.officeforstudents.org.uk/

The BPS (2016): Standards for the accreditation of undergraduate, conversion and integrated Masters programmes in psychology. Retrieved from: https://www1.bps.org.uk/system/files/Public\%20files/PaCT/Undergraduate\%20Accreditation \%202016 WEB.pdf

The Educational Support Partnership (2018). Retrieved from:

https://www.educationsupportpartnership.org.uk/

The Key (2017). State of Education Survey Report 2017. Retrieved from: https://stateofed.thekeysupport.com/

The Times Top One Hundred Graduate Employers for 2017-2018. The Times. Retrieved from: http://www.top100graduateemployers.com/employers

Thich Nhat Hanh \& Weare, K. (2017). Happy Teachers Change the World. London: Parallax Press

UCU (2018) Higher Education Branch Access Note. Retrieved from http://www.ucu.org.uk/media/9311/UCUBANHE29/pdf/HE_Pay_claim_submitted.pdf.

Universities UK (2018). Regulation of Higher Education. Retrieved from: https://www.universitiesuk.ac.uk/policy-and-analysis/Pages/regulation.aspx

Universities UK (2016). New programme to address mental health and wellbeing in universities. Retrieved from: https://www.universitiesuk.ac.uk/news/Pages/New-programmeto-address-mental-health-and-wellbeing-in-universities.aspx

Universities UK (2018). Regulation of Higher Education. Retrieved from: https://www.universitiesuk.ac.uk/policy-and-analysis/Pages/regulation.aspx

Yalom, I. \& Leszsz, M. (2005). The theory and practice of group psychotherapy. $\left(5^{\text {th }}\right.$ ed.). New York: Basic Books.

Wang, X., Cai, L., Qian, J., \& Peng, J. (2014). Social support moderates stress effects on depression. International Journal of Mental Health Systems, 8, 41. (on line) doi: $10.1186 / 1752-4458-8-41$ 
(C) Springer Nature Switzerland AG 2019. This is a post-peer-review, pre-copyedit version of a chapter published in the 'Values of the University in a Time of Uncertainty'. The final authenticated version is available online at: https://doi.org/10.1007/978-3-030-15970-2_18 Weng, H. Y., Fox, A. S., Shackman, A. J., Stodola, D. E., Caldwell, J. Z., Olson, M. C., ... Davidson, R. J. (2013). Compassion training alters altruism and neural responses to suffering. Psychological science, 24(7), 1171-1180.

Welford, M., \& Langmead, K. (2015). Compassion-based initiatives in educational settings. Educational and Child Psychology, 32(1), 71-80.

Weng, H. Y., Lapate, R. C., Stodola, D. E., Rogers, G. M., \& Davidson, R. J. (2018). Visual attention to suffering after compassion training is associated with decreased amygdala responses. Frontiers in Psychology, 9, 771.

Wood, A. M., Froh, J. J., \& Geraghty, A. W. (2010). Gratitude and well-being: A review and theoretical integration. Clinical psychology review, 30(7), 890-905.

YouGovUK (2016) One in four students suffers from mental health problems. Retrieved from: https://yougov.co.uk/news/2016/08/09/quarter-britains-students-areafflicted-mental-hea/ 
(C) Springer Nature Switzerland AG 2019. This is a post-peer-review, pre-copyedit version of a chapter published in the 'Values of the University in a Time of Uncertainty'. The final authenticated version is available online at: https://doi.org/10.1007/978-3-030-15970-2_18

\section{Figure 1:}

Core Assessment/Marking Criteria for use of the Micro Skills of Compassion in discussion group work

(Allocated 10\% - 35\% of marks in current HE practice)

\begin{tabular}{llllll}
\hline $\begin{array}{l}\text { Category of } \\
\text { Assessment }\end{array}$ & $\begin{array}{l}\text { Distinction } \\
(\mathbf{7 0} \%+)\end{array}$ & $\begin{array}{l}\text { Commendatio } \\
\text { n }\end{array}$ & $\begin{array}{l}\text { Pass } \\
(59-50 \%)\end{array}$ & $\begin{array}{l}\text { Marginal fail } \\
\text { F (49-40\%) }\end{array}$ & $\begin{array}{l}\text { Clear fail } \\
(\text { below 40\%) * }\end{array}$ \\
& & $69-60 \%)$ & & &
\end{tabular}


(C) Springer Nature Switzerland AG 2019. This is a post-peer-review, pre-copyedit version of a chapter published in the 'Values of the University in a Time of Uncertainty'. The final authenticated version is available online at: https://doi.org/10.1007/978-3-030-15970-2_18

1.

Research

Skills ?

1.2

Criticality/

analytical

thinking ?

2.1

Compassionate group management
Excellent use of eye contact and inclusive body language;

eliciting, encouraging and acknowledging the contributions of others; asking for clarity or elaboration; checking the understanding of the group.
Very good use of eye contact and inclusive body language; eliciting, encouraging and acknowledging the contributions of others; asking for clarity or elaboration; checking the understanding of the group.
Good use of eye contact and inclusive body language; eliciting, encouraging and acknowledging the contributions of others; asking for clarity or elaboration; checking the understanding of the group.
Body language signals little interest in what is said by others, or may focus on one or two other students only. Either monopolises or makes little contribution to discussion. Speaks too fast, or inaudibly.
Body language signals little or no interest in what is said by others, or may focus on one other student only. Either monopolises or makes little contribution to discussion. Speaks too fast, or inaudibly.

* A grade of 0-19\% indicates that there is little or nothing of merit in the assignment. 